\title{
Cheating behaviors and related factors at a Korean dental school
}

\author{
Jinwoo Choi
}

College of Dentistry, Dankook University, Cheonan, Korea

Purpose: This study aimed to investigate students' cheating behaviors, perceptions, and risk factors for cheating.

Methods: The author conducted a questionnaire survey of 375 undergraduate students at the Dankook University College of Dentistry in 2017. The questionnaires consisted of three parts: individual information, a moral sensitivity test, and cheating behaviors. Students rated whether they were involved in 28 cheating behaviors and their intolerant attitude for each behavior. Each student received a cheating grade of severity and diversity from 0 to 4 according to the degree of commitment in cheating behaviors. Chi-square and correlation tests were performed among cheating grades, individual factors, and moral sensitivity.

Results: Most students admitted having engaged in at least one cheating behavior (92.2\%). School years, intolerant attitudes towards cheating, perceived prevalence, study time, and academic performance showed significant correlations with students' cheating grades. Conclusion: These findings indicated that cheating behaviors were a very serious and prevalent problem at this dental college in South Korea. This is a critical issue that must be addressed. Dental school faculty members need to work together to develop policies, ethics curriculum and to improve students' attitudes. It is also important to encourage students to learn and devote their time to study to reduce cheating behaviors.

Key Words: Dental education, Ethics, Korea

\section{Introduction}

Ethics are the moral principles or virtues that define what is good for individuals and society. Ethics are important factors in human society and affect numerous decisions in our lives. In particular, the ethical values of health professionals have been considered essential since the time of the ancient Greeks, as they are responsible for the health and welfare of patients, the public, and society as a whole. Professional associations and ac- creditation bodies currently emphasize the importance of ethics education and consider ethical reasoning to be an essential competency [1,2]. As health professionals, dentists should learn about ethics in dental school and be trained to engage in ethical behavior.

Although most dental school curricula do contain formal ethics classes, they account for approximately 26.5 class hours on average, making them a relatively small part of the entire dental curriculum [3,4]. More importantly, to know is one thing, and to behave is another, meaning that living an ethical life as a dentist
Received: May 8, 2019 • Revised: July 24, 2019 • Accepted: August 11, 2019 Corresponding Author: Jinwoo Choi (https://orcid.org/0000-0002-5515-5320) College of Dentistry, Dankook University, 119 Dandae-ro, Dongnam-gu, Cheonan 31116, Korea Tel: +82.41.550.1921 Fax: +82.40.550.1924 email: runnachv@gmail.com
Korean J Med Educ 2019 Sep; 31(3): 239-249.

https://doi.org/10.3946/kjme.2019.134

eISSN: 2005-7288

(C) The Korean Society of Medical Education. All rights reserved. This is an open-access article distributed under the terms of the Creative Commons Attribution Non-Commercial License (http:// creativecommons.org/licenses/by-nc/3.0/), which permits unrestricted non-commercial use, distribution, and reproduction in any medium, provided the original work is properly cited. 
cannot be attained overnight and is a never-ending duty. Bertolami [5] stated that it is a whole-life project. Many efforts are underway to improve formal ethical curricula, but the hidden curriculum, which we take for granted since it involves phenomena such as customs, rules, and cultures, is also important $[3,4,6]$.

Students learn about how to lead an ethical life from their surroundings, including parents, peers, faculty members, and the collegial environment as a whole. In college, academic integrity is one of the most important extracurricular domains as it reflects a shared set of principles including honesty, trust, fairness, and respect and it affects students' ethical development. Cheating is a form of academic misconduct that refers to behaviors to gain an unfair academic advantage over other students or to academically disadvantage other students in relation to oneself. Cheating not only undermines academic integrity itself, but also leads other students engage in cheating behaviors, because many students can justify their own behavior using the old adage, "If everyone is doing it, why shouldn't I $[7,8]$ ?" This vicious cycle is not only limited to dental schools, as academic dishonesty is also related to unprofessional behaviors, such as drug or alcohol abuse and negligence in clinical situations. Papadakis et al. [9] found that students who showed unprofessional behaviors at school were more likely to be identified as unprofessional in their clinical years.

Academic integrity is an important part of the hidden curriculum and should be maintained at a high level throughout the dental curriculum. However, previous reports about cheating behaviors of medical or dental college in South Korea are rare [10]. The Dankook University College of Dentistry has school policies for cheating and has formal ethics classes; nonetheless, cheating happens occasionally. Therefore, we conducted this study to investigate cheating behaviors, individual factors, attitudes, and moral sensitivity among students in order to characterize the current situation regarding cheating, students' perceptions, and related risk factors.

\section{Methods}

This study was approved by the Institutional Review Board of Dankook University (DKU 2017-05-023). A total of 375 undergraduate students in the first through sixth years of the curriculum at the Dankook University College of Dentistry took part in a self-administered survey. The survey was conducted at the end of the first semester of 2017. Students were informed about the survey in advance through the representative of each year, and questionnaires with a consent form were distributed at the main classroom after each school year's essential class. The author notified the students about the nature of the survey and their right to refuse to answer any questions or to stop their participation at any time. They were also assured of anonymity and confidentiality. The survey took less than 30 minutes to complete and no incentive was provided. After finishing the questionnaire, students submitted it to designated place voluntarily and there was no monitoring during the survey. The response rate was 86\% (375/432) and unreliable responses, such as serial 1-number checking or excessive blanks, were excluded. As a result, questionnaires from 319 students were used in this study. Table 1 shows the distribution of the participants by gender, school years, and cheating experience. The age of the participants ranged from 17 to 36 years, and the mean age was 22 years (Table 1).

\section{Questionnaires}

The questionnaires consisted of three parts representing: (1) individual student information; (2) moral sensitivity test; and (3) dental students' experience and 


\begin{tabular}{|c|c|c|c|c|}
\hline \multirow{2}{*}{ Variable } & \multicolumn{2}{|c|}{ Gender } & \multicolumn{2}{|c|}{ Cheating experience } \\
\hline & Male & Female & No & Yes \\
\hline Age (yr) & $22.5(17-36)$ & $21.9(18-35)$ & & \\
\hline \multicolumn{5}{|l|}{ School years } \\
\hline Pre-dental & 77 & 29 & 6 & 100 \\
\hline Pre-clinical & 111 & 45 & 15 & 141 \\
\hline Clinical & 43 & 14 & 4 & 53 \\
\hline \multicolumn{5}{|l|}{ Cheating experience } \\
\hline No & 20 & 5 & & \\
\hline Yes & 211 & 83 & & \\
\hline
\end{tabular}

Data are presented as mean (range) or number. No significant results by the chi-square test between items.

perceptions towards cheating behaviors.

The first part collected individual factors such as age, gender, school years, study time per week (on a 5-point Likert scale), volunteer experience (yes/no), economic conditions (no support from any source, partial support with a loan, partial support without a loan, full support) and grade point average (GPA; $\leq 2.5,2.51-3,3.01-3.5$, $3.51-4.0, \geq 4.01$ ), and a morality self-assessment question ("How moral do you think you are?" on a 7-point Likert scale).

To evaluate moral sensitivity, the three scenarios presented by Kim and Lee [11], which were developed to measure moral sensitivity in Korean teenagers using standardized methods, were adopted and modified to fit the context of dental college with the authors' permission (stories about copying an assignment, a leaked old test, and team assignments). Each scenario had 12 questions asking students to imagine that they were a main character and to respond about what they would think or do. We used six questions to evaluate participants' ability to interpret the situations and another six to evaluate their ability to project the result of students' actions. A 7-point Likert scale was used for every question.

For the last component, which investigated cheating behaviors, we adapted an inventory developed by Kwon et al. [12], which was originally developed for medical students in South Korea, after careful review. We developed some new questions to investigate cheating behaviors in specific situations that only dental students face. Those include the dental laboratory work environment, clinical observations, and assisting situations during the pre-clinical and clinical curriculum in Korean dental schools. As a result, a total of 28 questions were selected and reviewed by a group of under-graduate dental students and residents to ensure that the questions were delivered without any misunderstandings. In the survey, the students rated their experience of having engaged in each behavior (yes/no), attitude towards the behaviors (no problem/acceptable on occasion/possibly unacceptable/definitely unacceptable), and perceived prevalence (no one/a few/some/everyone does it) for all of the 28 items.

\section{Cheating severity and diversity}

The students' cheating experience was converted into two indicators representing their severity and diversity. Firstly, 28 cheating behaviors were classified into four groups according to students' attitude towards each behavior as follows: (1) group A: more than 3/4 of students replied that it was definitely unacceptable; (2) group B: more than $2 / 4$ of students replied that it was definitely unacceptable; (3) group $\mathrm{C}$ : more than 1/4 of students replied that it was definitely unacceptable; and 
(4) group D: fewer than 1/4 of students replied that it was definitely unacceptable.

Each student received a severity grade of 0 to 4 according to the most unacceptable behaviors they had committed as follows: (1) severity grade 0: who did not commit any cheating behaviors; (2) severity grade 1: who committed only group D cheating behaviors; (3) severity grade 2: who committed group $\mathrm{C}$ behaviors (except A and B); (4) severity grade 3: who committed group B behaviors (except A); and (5) severity grade 4: who committed group A behaviors.

Each student received a diversity grade of 0 to 3 according to the number of admitted behaviors as follows: (1) diversity grade 0: who did not commit any cheating behaviors; (2) diversity grade 1: who committed one or two types of cheating behaviors; (3) diversity grade 2: who committed three to five types of cheating behaviors; and (4) diversity grade 3: who committed more than six types of cheating behaviors.

\section{Statistics}

The internal consistency and validity of the moral sensitivity tests were evaluated using IBM SPSS ver. 21.0 (IBM Corp., Armonk, USA). The Pearson and Spearman correlation tests were used to evaluate relationships among the cheating indicators of students, individual factors, attitudes, perceived prevalence, and moral sensitivity. The statistical significance level of $\mathrm{p}<0.05$ was used.

\section{Results}

Validity for moral sensitivity tests was evaluated by exploratory factor analysis for 36 questions, and 11 questions that were erroneous from survey's intention were excluded, and 25 questions were re-analyzed. Table 2 presents rotated factor matrix of 25 moral sensitivity questions, and Kaiser-Meyer-Olkin value was 0.804

\begin{tabular}{|c|c|c|c|c|c|c|c|}
\hline & \multirow{2}{*}{ Item } & \multicolumn{6}{|c|}{ Factor } \\
\hline & & 1 & 2 & 3 & 4 & 5 & 6 \\
\hline \multicolumn{8}{|l|}{ Story 1} \\
\hline \multirow[t]{3}{*}{ Situation interpretation } & $01 \_1$ & 0.770 & 0.040 & 0.069 & 0.049 & 0.023 & -0.044 \\
\hline & $01 \_2$ & 0.655 & 0.180 & 0.153 & 0.055 & 0.074 & -0.004 \\
\hline & 014 & 0.587 & 0.000 & 0.011 & 0.026 & 0.223 & 0.069 \\
\hline \multirow[t]{4}{*}{ Result projection } & $01-9$ & 0.100 & 0.677 & -0.106 & 0.134 & 0.250 & -0.005 \\
\hline & $01-10$ & 0.044 & 0.678 & 0.035 & 0.258 & 0.117 & -0.101 \\
\hline & $01-11$ & 0.049 & 0.874 & 0.182 & -0.009 & -0.021 & 0.080 \\
\hline & $01^{-} 12$ & 0.071 & 0.861 & 0.166 & 0.000 & 0.010 & 0.073 \\
\hline \multicolumn{8}{|l|}{ Story 2} \\
\hline \multirow[t]{4}{*}{ Situation interpretation } & $02 \_1$ & 0.320 & 0.109 & 0.645 & 0.295 & -0.039 & 0.039 \\
\hline & $02-2$ & -0.054 & -0.009 & 0.706 & -0.037 & 0.273 & -0.010 \\
\hline & $02-3$ & 0.102 & 0.087 & 0.751 & 0.101 & 0.105 & 0.116 \\
\hline & $02-4$ & 0.183 & 0.131 & 0.580 & 0.443 & 0.161 & -0.036 \\
\hline \multirow[t]{6}{*}{ Result projection } & $02-7$ & 0.017 & 0.011 & -0.107 & 0.744 & 0.054 & 0.089 \\
\hline & $02-8$ & 0.045 & 0.126 & 0.188 & 0.518 & -0.012 & -0.014 \\
\hline & 02_9 & 0.202 & 0.109 & 0.196 & 0.619 & -0.053 & -0.149 \\
\hline & $02-10$ & -0.036 & -0.068 & -0.067 & 0.632 & 0.321 & 0.151 \\
\hline & 02 & -0.142 & 0.261 & 0.439 & 0.532 & -0.119 & 0.176 \\
\hline & $02 \_12$ & 0.065 & 0.134 & 0.414 & 0.628 & 0.075 & 0.046 \\
\hline
\end{tabular}




\begin{tabular}{|c|c|c|c|c|c|c|c|}
\hline & \multirow{2}{*}{ Item } & \multicolumn{6}{|c|}{ Factor } \\
\hline & & 1 & 2 & 3 & 4 & 5 & 6 \\
\hline \multicolumn{8}{|l|}{ Story 3} \\
\hline \multirow[t]{4}{*}{ Situation interpretation } & 03_2 & 0.214 & 0.072 & 0.367 & 0.075 & 0.697 & 0.108 \\
\hline & 03_3 & 0.248 & 0.094 & 0.300 & 0.133 & 0.648 & 0.059 \\
\hline & 03_4 & 0.270 & 0.319 & 0.182 & 0.287 & 0.421 & -0.009 \\
\hline & 03_6 & -0.030 & 0.170 & -0.087 & -0.050 & 0.576 & 0.371 \\
\hline \multirow[t]{4}{*}{ Result projection } & $03 \_7$ & 0.244 & -0.062 & 0.020 & 0.132 & -0.162 & 0.655 \\
\hline & $03 \_8$ & 0.090 & -0.017 & 0.034 & 0.122 & 0.221 & 0.756 \\
\hline & 03_9 & -0.220 & 0.161 & -0.025 & -0.150 & 0.157 & 0.648 \\
\hline & 03 & -0.069 & -0.031 & 0.137 & 0.032 & 0.105 & 0.760 \\
\hline
\end{tabular}

Extraction method was by principal component analysis. Rotation method was by varimax with Kaiser normalization. Kaiser-Meyer-Olkin measure of sampling adequacy $=0.804(p<0.05)$. Cronbach $a=0.823$. Bold typed items are loaded strongly on each Factor.

Table 3. Group Classification and Frequency of 28 Cheating Behaviors

\begin{tabular}{|c|c|c|}
\hline Behavior group ${ }^{\text {a) }}$ & Behaviors & Frequency $(\%)$ \\
\hline \multirow[t]{8}{*}{ A } & Getting leaked test questions prior to the exam & 8.2 \\
\hline & Writing patient records without physical examination in charting practices & 5.3 \\
\hline & Submitting others' lab-work as your own & 4.7 \\
\hline & Copying peers' answers on written exams & 1.9 \\
\hline & Pleading with faculty to alter the class attendance list & 1.3 \\
\hline & Using crib sheets on written exams & 0.9 \\
\hline & Pleading with faculty to get higher grades & 0.6 \\
\hline & Pleading with faculty to raise exam scores & 0.3 \\
\hline \multirow[t]{7}{*}{ B } & Submitting peers' clinical assist records as your own & 22.8 \\
\hline & Getting assist records from a close resident without assist work & 17.5 \\
\hline & Copying peers' answers on class quizzes & 10.0 \\
\hline & Cutting in waiting-list in clinical practices & 7.0 \\
\hline & Leading patients to have unnecessary treatment for your practice & 7.0 \\
\hline & Copying ideas for homework from peers & 4.4 \\
\hline & Faking documents to excuse class absences & 3.4 \\
\hline \multirow[t]{11}{*}{ C } & Leaving class after signing the attendance list & 34.5 \\
\hline & Shifting patient care to peers during exam periods & 33.3 \\
\hline & Stealing practice instruments from peers & 26.8 \\
\hline & Intentionally skipping waiting-list turn to avoid difficult cases or faculty members & 24.6 \\
\hline & Asking a friend to sign the class attendance list & 21.3 \\
\hline & Faking experimental data for reports & 17.9 \\
\hline & Leaving team practice after signing the attendance list & 16.0 \\
\hline & Buying reports from the internet & 15.4 \\
\hline & Asking peers to do homework for you & 10.7 \\
\hline & Free riding in team project & 10.3 \\
\hline & Being absent from team practice & 9.9 \\
\hline \multirow[t]{2}{*}{ D } & Getting reports from a prior year & 74.6 \\
\hline & Copying homework & 61.4 \\
\hline
\end{tabular}

alGroup A: more than 3/4 of students replied that it was definitely unacceptable; group B: more than $2 / 4$ of students replied that it was definitely unacceptable; group C: more than 1/4 of students replied that it was definitely unacceptable; and group D: fewer than $1 / 4$ of students replied that it was definitely unacceptable. 
$(p<0.05)$; this showed meritorious validity. The Cronbach $\alpha$ value for the moral sensitivity tests was 0.823 ; this showed good internal consistency among the scenarios and proved that the moral sensitivity tests were reliable for this study.

\section{Severity and prevalence of cheating be- haviors}

Table 3 shows the severity and prevalence of 28 cheating behaviors. The most serious behaviors were 'getting leaked test questions prior to the exam,' 'writing patient records without physical examination in charting practices', and 'submitting other's lab-work as your own,' while the most frequent behaviors were 'getting reports from a prior year,' 'copying homework,' and 'leaving class after signing the attendance list.'

\section{Cheating experience of students and re- lated factors}

Table 4 shows the cross-tabulation of severity and diversity of students according to GPA and school years. Most students admitted having engaged in at least one cheating behavior $(294 / 319,92.2 \%)$. The number of serious cheaters (grade 4) was 41 (12.9\%), and as the year in school increased, the cheating severity of the students also increased (Tables 4, 5).

Table 4. Cross-Tabulation between Academic Performance, School Years, and Cheating Experience of Students

\begin{tabular}{|c|c|c|c|c|c|c|c|c|c|c|}
\hline \multirow{2}{*}{ Variable } & \multirow{2}{*}{ Category } & \multicolumn{5}{|c|}{ Severity grade ${ }^{\text {al }}$} & \multicolumn{4}{|c|}{ Diversity grade ${ }^{\text {bl }}$} \\
\hline & & 0 & 1 & 2 & 3 & 4 & 0 & 1 & 2 & 3 \\
\hline \multirow[t]{3}{*}{$\mathrm{GPA}^{\mathrm{cl}}$} & $\leq 2.5$ & 3 & 3 & 24 & 7 & 11 & 3 & 13 & 21 & 11 \\
\hline & $2.51-3.5$ & 13 & 24 & 65 & 23 & 20 & 13 & 46 & 62 & 24 \\
\hline & $\geq 3.51$ & 6 & 17 & 41 & 16 & 10 & 6 & 33 & 44 & 7 \\
\hline \multirow[t]{3}{*}{ School years ${ }^{d !}$} & Pre-dental (1-2) & 6 & 14 & 75 & 7 & 4 & 6 & 32 & 57 & 11 \\
\hline & Pre-clinical (3-5.5) & 15 & 33 & 65 & 22 & 21 & 15 & 56 & 63 & 22 \\
\hline & Clinical $(5.5-6)$ & 4 & 4 & 15 & 18 & 16 & 4 & 17 & 27 & 9 \\
\hline
\end{tabular}

GPA: Grade point average.

${ }^{\text {a) }}$ Severity grade 0: who did not commit any cheating behaviors; grade 1: committed group D cheating behaviors; grade 2: committed group $\mathrm{C}$ and $D$ cheating behaviors; grade 3: committed group B to $D$ cheating behaviors; grade 4: who committed group $A$ to $D$ cheating behaviors. ${ }^{b}$ Diversity grade 0: who did not commit any cheating behaviors; grade 1: committed one or two types of cheating behaviors: grade 2: committed three to five types of cheating behaviors; grade 3: who committed more than six types of cheating behaviors. ${ }^{c l} 1$ st year students did not have GPA point and excluded. ${ }^{\text {d) }}$ Among four variables, only school years and severity grade showed statistically significant result by the chi-square test $(p<0.05)$.

Table 5. Correlations among Students' Cheating Grades and Other Factors (p-Values and Correlation Coefficient)

\begin{tabular}{|c|c|c|c|c|c|}
\hline Factors & Severity grade & Diversity grade & Attitudes (intolerance) & Perceived prevalence & Moral sensitivity \\
\hline Severity grade & - & $0.00^{a)}(0.72)$ & $0.00^{a l}(-0.38)$ & $0.00^{\mathrm{a})}(-0.33)$ & 0.69 \\
\hline Diversity grade & $0.00^{\mathrm{a})}(0.72)$ & - & $0.00^{\mathrm{al}}(-0.44)$ & $0.00^{\mathrm{al}}(-0.37)$ & 0.117 \\
\hline Gender & 0.46 & 0.88 & 0.69 & 0.87 & 0.05 \\
\hline Age & $0.00^{\mathrm{a})}(0.18)$ & 0.95 & 0.45 & 0.22 & 0.09 \\
\hline Attitude (intolerance) & $0.00^{\mathrm{a})}(-0.38)$ & $0.00^{\mathrm{al}}(-0.44)$ & - & $0.00^{b)}(0.48)$ & $0.04^{\mathrm{bl}}(0.12)$ \\
\hline Perceived prevalence & $0.00^{\mathrm{a})}(-0.33)$ & $0.00^{a)}(-0.37)$ & $0.00^{b)}(0.48)$ & - & 0.49 \\
\hline School years & $0.00^{\mathrm{a})}(0.22)$ & 0.87 & 0.61 & 0.12 & $0.04^{a)}(-0.11)$ \\
\hline Grade point average & $0.04^{\mathrm{a})}(-0.12)$ & $0.01^{a)}(-0.16)$ & 0.65 & 0.32 & 0.21 \\
\hline Study time/wk & $0.00^{\mathrm{a})}(-0.19)$ & $0.00^{a)}(-0.23)$ & $0.01^{\text {a) }}(0.16)$ & 0.58 & 0.48 \\
\hline Self moral assessment & 0.63 & 0.26 & 0.11 & 0.18 & $0.00^{\mathrm{a})}(0.24)$ \\
\hline Economic conditions & 0.85 & 0.84 & 0.81 & 0.77 & 0.26 \\
\hline Volunteer experience & 0.69 & 0.35 & 0.85 & 0.35 & $0.00^{a)}(-0.16)$ \\
\hline Moral sensitivity & 0.69 & 0.12 & $0.04^{b /}(0.12)$ & 0.49 & - \\
\hline
\end{tabular}

${ }^{\text {a) }}$ Significant by the Spearman correlation test. b)Significant by the Pearson correlation test. 
Table 5 shows correlations among the cheating severity and diversity, and other factors. Firstly, severity grade had a strong correlation with cheating diversity (0.72). Severity and diversity grades had significant negative correlations with intolerant attitude, perceived prevalence, GPA, and study time per week. Intolerant attitude towards cheating had positive correlations with perceived prevalence (0.48), study time (0.16), and moral sensitivity (0.12). School years showed a positive correlation with cheating severity (0.22) and negative correlation with moral sensitivity (-0.11). Moral sensitivity showed negative correlations with school years, and volunteer experience, and showed positive correlations with intolerant attitude and self moral assessment. However, it didn't show any correlations with cheating severity nor cheating diversity.

\section{Discussion}

Academic dishonesty has been a serious problem for decades, as cheating behaviors compromise the effects of education and hinder the accomplishment of educational goals. This is the first study which investigated cheating severity, diversity, and related factors at a dental college in South Korea. Unfortunately, most students $(n=294$, 92.2\%) admitted having engaged in at least one cheating behavior. These results are comparable with previous studies, in which the reported cheating rates were 52.5\% (Jurdi et al. [7] in 2011), 75\% (Andrews et al. [8] in 2007), 80\% (Aggarwal et al. [13] in 2002), 91\% (Henning et al. [14] in 2013), 94\% (Hrabak et al. [15] in 2004), and 99.8\% (Vengoechea et al. [16] in 2008). Among the 28 cheating behaviors that we investigated, the behaviors considered most serious by students were getting leaked exam questions, writing false records in charting practice, submitting others' lab-work as their own, cheating on written exams, and pleading with faculty to alter their exam score or attendance records. The cheating behaviors perceived to be the least serious were getting reports from a prior year and copying homework. Although a policy prohibiting plagiarism and cheating exists, it does not give any detailed examples of cheating. Nonetheless, the students were able to differentiate various levels of cheating behaviors. Cheating on exams and forgery were considered to be very serious behaviors, while copying and signing the attendance list for peers were not, and these findings are consistent with previous reports $[14,15,17,18]$.

Yang [19] reported the cheating rate (69\%) of Korean undergraduate students, and his result is relatively lower than the cheating rate (92\%) of this study. However, his study was conducted on college students without distinction of students' major, and direct comparison would not be appropriate among study results. Lee [20] reported that students with a science major cheated more on exams than students who majored in art or literacy. Nature and workload may vary according to students' major, and excessive academic workload may be one of the cheating reasons in dental or medical schools. However, studies addressing cheating differences according to students' majors are rare, and further researches are required.

Many studies have reported that students who were more lenient towards cheating were more likely to engage in cheating behaviors $[7,14,15]$. The results of this study are consistent with previous studies in this regard. Cheating severity and diversity had negative correlation coefficient with intolerant attitude, GPA, and study time. These results show that students who cheat more often tend to be lenient to cheating, study less, and get lower GPA, and attitude was the strongest factor. However, some researchers suggested that attitudes may be the result of justification rather than the cause of 
behaviors, or that they may have a reciprocal relationship [7,21]. Although, causal relationship is not clear, attitudes and behaviors are closely related, and it is important to improve attitudes towards cheating behaviors. Bolin [21] suggested that influencing attitudes would be a cost-efficient way of reducing cheating behaviors, instead of influencing the self-control trait of students or their perceived cheating opportunities.

An interesting result of this study is the negative relationship between the perceived prevalence of cheating by peers and students' cheating grades. These results are not only in disagreement with our commonsense intuitions, but also differ from those of previous studies $[7,15,22]$. It seems that students who did not engaged in cheating and who are intolerant about it, feel more disadvantaged and tend to overestimate the prevalence of cheating behaviors. This is supported by the result of positive correlation between intolerant attitude and perceived prevalence. Although there are some discrepancies among previous studies in terms of results and study designs, it seems clear that cheating by peers is a related factor to cheating, but it may not be critical. Hrabak et al. [15] stated that 'perceived prevalence of cheating as a perception of peer group behavior, was consistent but was not the strongest predictor,' and Jordan [22] stated 'unexpectedly, both groups (cheaters and non-cheaters) underestimated actual cheating levels.' Considering previous reports, perceived prevalence is a subjective feeling, and it may be different according to the situation of each survey and college.

Moral sensitivity is the personal ability to recognize moral issues in a given situation and is one of the components of Rest's four-components model [23]. The model's four components are moral sensitivity, moral judgment, moral motivation, and moral character, and the model describes ethical behaviors as the result of these four psychological processes [23]. Moral sensitivity had a positive correlation with attitudes towards cheating behavior and self-moral assessment scores, but it was not related to cheating behavior (severity and diversity) itself or volunteer experiences. These results suggest that moral sensitivity only affects the recognition of ethical issues, not behaviors. Interestingly, moral sensitivity decreased as year in school increased, and this result corresponds with previous studies. Lee et al. [24] reported that moral sensitivity decreased in the fifth and the sixth years during medical school curricula, in contrast to the third and fourth years. Akabayashi et al. [25] showed similar results, with moral sensitivity decreasing in the sixth year and during residency in comparison to the fourth and fifth years. However, some studies reported different results. Bebeau et al. [26] suggested that moral sensitivity improved with dental education, and a cohort study of Patenaude et al. [27] showed a declined leveling process, suggesting the effect of the hidden curriculum during medical school.

We found a significant correlation between cheating behaviors and school years in this study. This is consistent with the results of Vengoechea et al. [16], who suggested that being in a more advanced academic semester was a risk factor for misconduct. School years did not show a direct correlation with attitudes but had correlations with decreased moral sensitivity and increased cheating severity. These results suggest that ethical reasoning decreased in higher school year students. Some previous studies have shown similar effects of school years. Crandall et al. [28] reported that the attitudes of fourth-year male students were worse than those of first-year students. Satterwhite et al. [29] also reported that exposure to unethical behavior started early and continued to increase with each year in medical school. It is not certain that the hidden curriculum had negative influences on those results, but 
year in school is still postulated to be a considerable factor.

Plagiarism and cheating have been a major concern in North American dental schools, and many studies have been carried out [3-6,8]. Possible reasons for cheating can include pressure of study burdens, stress of competition, fear of failing, low risk of being caught and penalty, and so forth [8]. In order to enhance academic integrity, previous reports recommended introducing an honor code, enforcement of integrity policy and guidelines, encouraging report of students' cheating, and faculty education. With regard to faculty members, stop using old exams, more active proctoring, and more support of administration were recommended also $[8,10]$. Honor code is required for disciplinary action and can be an evidence for potential lawsuits, they are also useful in terms of students education. Honor codes have been reported to have the effect of preventing academic dishonesty [8,10]. McCabe et al. [30] modified the honor code and it was associated lower levels of student dishonesty.

In this study, we investigated the severity and diversity of academic dishonesty among students, and their attitude towards cheating, moral sensitivity, and individual factors. Students' moral sensitivity was related to their attitude and decreased as year in school increased. However, actual cheating behaviors were not related to moral sensitivity but to their attitude, school year, study time, and GPA. These results suggest that students who are not prepared, are more likely to engage cheating behaviors. Introducing an honor code and pledge, developing a detailed academic integrity policy, and ethics curriculum are necessary, but it is also important to encourage students to learn and to devote their time to study. Dental school administrators and faculty members also need to work together to improve academic integrity.
The present study has a few limitations that must be acknowledged. Firstly, this study only addressed academic misconduct. Non-academic misconduct and professional misconduct should also be considered, since they influence students' learning environment as part of the hidden curriculum. Secondly, other factors such as sanctions, students' workload, and stress levels should be considered in future researches as well.

\section{ORCID:}

Jinwoo Choi: https://orcid.org/0000-0002-5515-5320

Acknowledgements: None.

Funding: The present research was conducted with funding from the research fund of Dankook University in 2017.

Conflicts of interest: No potential conflict of interest relevant to this article was reported.

Author contributions: All work was done by Jinwoo Choi.

\section{References}

1. American Dental Association. ADA Principles of Ethics and Code of Professional Conduct. http://www.ada.org en/about-the-ada/principles-of-ethics-code-of-professionalconduct. Published September 2018. Accessed April 30, 2019.

2. Commission of Dental Accreditation. Accreditation Standards for Dental Education Programs. http://www. ada.org/ $/$ media/CODA/Files/pde.pdf?la=en. Published January 1, 2018. Accessed April 30, 2019.

3. Lantz MS, Bebeau MJ, Zarkowski P. The status of ethics teaching and learning in U.S. dental schools. J Dent Educ. 201 1;75(10):1295-1309.

4. Masella RS. Renewing professionalism in dental educa- 
tion: overcoming the market environment. J Dent Educ. 2007;71(2):205-216.

5. Bertolami CN. Why our ethics curricula don't work. J Am Coll Dent. 2006;73(2):35-46.

6. Masella RS. The hidden curriculum: value added in dental education. J Dent Educ. 2006;70(3):279-283.

7. Jurdi R, Hage HS, Chow HP. Academic dishonesty in the Canadian classroom: behaviours of a sample of university students. Can J High Educ. 2011;41(3):1-35.

8. Andrews KG, Smith LA, Henzi D, Demps E. Faculty and student perceptions of academic integrity at U.S. and Canadian dental schools. J Dent Educ. 2007;71(8):10271039.

9. Papadakis MA, Teherani A, Banach MA, et al. Disciplinary action by medical boards and prior behavior in medical school. N Engl J Med. 2005;353(25):2673-2682.

10. Kim HK, Lee JH, Kim SH, Baek JH, Han JS, Rhyu IC. A study on academic integrity in dental education. J Korean Dent Assoc. 2017;55(3):215-228.

11. Kim YH, Lee SH. A study of the development of the Korean youth moral test: standardization of the test and categorization of moral type. J Ethics Educ Stud. 2013; 31:237-260.

12. Kwon HJ, Lee YM, Lee YH. Development of an inventory assessing medical students' attitudes towards academic misconduct. Korean J Med Educ. 2013;25(3): $211-220$.

13. Aggarwal R, Bates I, Davies G, Khan I. A study of academic dishonesty among students at two pharmacy schools. Pharm J. 2002;269(7219):529-533.

14. Henning MA, Ram S, Malpas P, Shulruf B, Kelly F, Hawken SJ. Academic dishonesty and ethical reasoning: pharmacy and medical school students in New Zealand. Med Teach. 2013;35(6):el211-el217.

15. Hrabak M, Vujaklija A, Vodopivec I, Hren D, Marusić M, Marusić A. Academic misconduct among medical students in a post-communist country. Med Educ. 2004;
38(3):276-285.

16. Vengoechea J, Moreno S, Ruiz A. Misconduct in medical students. Dev World Bioeth. 2008;8(3):219-225.

17. Al-Dwairi ZN, Al-Waheidi EM. Cheating behaviors of dental students. J Dent Educ. 2004;68(11):1192-1195.

18. Asokan S, John JB, Janani D, Jessy P, Kavya S, Sharma K. Attitudes of students and teachers on cheating behaviors: descriptive cross-sectional study at six dental colleges in India. J Dent Educ. 2013;77(10):1379-1383.

19. Yang DG. The relationships among undergraduates' perception and behavior of cheating in examinations and their academic achievement. Korean J Couns Psychother. 2003;15:615-631.

20. Lee $\mathrm{OH}$. Relationship of antisociality and cheating behavior of undergraduates by their sex, grade and major. Korean J Youth Stud. 2009;16:1-25.

21. Bolin AU. Self-control, perceived opportunity, and attitudes as predictors of academic dishonesty. J Psychol. 2004;138(2):101-114.

22. Jordan AE. College student cheating: the role of motivation, perceived norms, attitudes, and knowledge of institutional policy. Ethics Behav. 2001;11(3):233-247.

23. Rest JR. Moral development: advances in research and theory. New York, USA: Praeger; 1986.

24. Lee JH, Moon YL, Kim JY, Son HJ, Hong KP. A study of comparison between moral sensitivity and reasoning in medical students. Korean J Med Educ. 2006;18(1): 41-53.

25. Akabayashi A, Slingsby BT, Kai I, Nishimura T, Yamagishi A. The development of a brief and objective method for evaluating moral sensitivity and reasoning in medical students. BMC Med Ethics. 2004;5:E1.

26. Bebeau MJ, Rest JR, Yamoor CM. Measuring dental students' ethical sensitivity. J Dent Educ. 1985;49(4): 225-235.

27. Patenaude J, Niyonsenga T, Fafard D. Changes in students' moral development during medical school: a 
cohort study. CMAJ. 2003;168(7):840-844.

28. Crandall SJ, Volk RJ, Loemker V. Medical students' attitudes toward providing care for the underserved: are we training socially responsible physicians? JAMA. 1993;269(19):2519-2523.

29. Satterwhite WM 3rd, Satterwhite RC, Enarson CE.
Medical students' perceptions of unethical conduct at one medical school. Acad Med. 1998;73(5):529-531.

30. McCabe DL, Trevino LK, Butterfield KD. Honor codes and other contextual influences on academic integrity: a replication and extension to modified honor code settings. Res High Educ. 2002;43(3):357-378. 